\title{
LA TRANSICION DE LA VELA AL VAPOR \\ EN LA FLOTA MERCANTE ESPAÑOLA: \\ CAMBIO TECNICO Y ESTRATEGIA \\ EMPRESARIAL
}

JESUS M.a VALDALISO

Universidad del Pais Vasco

\section{RESUMEN}

En España los pocos trabajos que analizan la transición de la vela al vapor en la flota mercante española lo hacen en términos de fracaso y decadencia. Sin embargo, esa impresión no concuerda bien con las magnitudes cuantitativas internacionales disponibles que sitúan a la flota mercante española como una de las primeras en cuanto al grado de difusión del buque de vapor en las tres últimas décadas del siglo XIX. El objetivo de este artículo es analizar el proceso de cambio técnico, institucional y organizativo de la marina mercante española durante la segunda mitad del siglo XIX y la estrategia empresarial de los navieros españoles ante el mismo.

\section{ABSTRACT}

The few works which talk about the transition from sail to steam in the Spanish merchant marine, analyze it in terms of decadence and failure. But these impressions do not pair with an analysis of the Spanish fleet from an international perspective: it was among the pionneers, together with Great Britain, to complete the technological modernization of its ships. The objective of this paper is to describe and explain the process of technical diffusion, the changes in the institutional framework, and the business strategy of Spanish shipowners in this context.

La difusión del hierro como material y del vapor como fuerza propulsora en los buques constituye el cambio tecnológico fundamental que tiene lugar durante el siglo XIX en la navegación marítima. Los primeros vapores que navegaron en los años treinta y cuarenta de esa centuria consumían una gran cantidad de carbón, alrededor de 4-5 kilogramos por caballo de fuerza y por 
hora, y tenían una maquinaria muy pesada y unas calderas de grandes dimensiones que reducían considerablemente el espacio disponible para carga. Su mayor rapidez tenía que ser pagada a un precio muy superior al de los buques de vela y, en la práctica, su participación en el transporte marítimo en esas décadas no dejaba de ser testimonial. Sin embargo, antes de mediados de la centuria dos grandes innovaciones se habian generalizado junto con la ! utilización del motor simple de vapor: el uso del hierro como materia prima del casco de los buques - que con un peso inferior en un 30-40 por 100 al de un buque de madera del mismo desplazamiento tenía una capacidad de carga superior en un 15 por 100 - y la sustitución de la rueda de palas por la hélice (1838), especialmente adecuada para la navegación oceánica. Una tercera innovación - el descubrimiento del condensador de superficie que permitía reciclar el agua destilada en las calderas y eliminaba el uso de agua salada que tanto perjudicaba a éstas - se produjo en 1834, pero su aplicación no pudo generalizarse hasta los años sesenta ${ }^{1}$. A partir de esta base técnica la evolución en las décadas siguientes fue dirigida a reducir el consumo de combustible y a incrementar el espacio de carga, lo que se va a conseguir con sucesivos perfeccionamientos en el motor de vapor y en las calderas. El desartollo del motor compuesto y el aumento de las presiones obtenidas en las calderas en los años sesenta y setenta redujo el consumo de combustible en un 40 por 100, y la reducción del peso y el tamaño de las máquinas dejó más espacio libre para la carga. Finalmente, la aplicación del motor de triple expansión en los ochenta disminuyó aún más el consumo de combustible, y la utilización del acero Siemens mejoró sensiblemente la eficiencia de máquịnas y calderas ${ }^{2}$.

La mayor parte de los autores que han investigado este fenómeno coinciden en interpretarlo como un proceso gradual que se lleva a cabo con una cierta lentitud. Blake señalaba que «el cambio de la vela y la madera al vapor y el hierro fue sísmico en su efecto final, pero el proceso fue muy lento, con innumerables superposiciones de tradición e innovación, de viejas y nuevas prácticas» ${ }^{3}$. Graham (1956) fue el primero en advertir la coincidencia

1 Los depósitos de sal que se formaban en las calderas, además de limitar la presión de las mismas y reducir su vida de uso, requerían una limpieza periódica. La introducción del condensador, patentado por Samuel Hall, además de aumentar la vida de las calderas permitió la consecución de mayores presiones y redujo el consumo de carbón. Sobre el condensador y las otras innovaciones, véase Palmer (1978), pp. 240-41; Headrick (1988), pp. 24-25, y Jackson (1988), pp. 263-65.

2 Sobre este tema, véase Craig (1980), pp. 5-16. Una bibliografia más detallada en Valdaliso (1991a), en prensa.

3 Blake (1960), p. 40 (traducción mía, J. V.). 
entre el inicio de la difusión del vapor en la navegación y la época dorada del buque de vela desde 1850 hasta 1885. Harley (1971), en un modelo neoclásico, interpreta la transición en función de los costes relativos de ambos tipos de navegación. La relativa duración de ese período se debería a la necesidad de los vapores de transportar su propio combustible: los inputs necesarios y los costes de transporte en los vapores variaban inversamente con la distancia del viaje desde el punto de carga. Para Rosenberg la lentitud de la transición se debe a que, como en todos los procesos de difusión tecnológica, se produjo no sólo un desarrollo gradual de la nueva tecnología, sino también de la vieja. En el corto plazo, las mejoras en los buques de vela y los problemas marginales en la oferta de los buques de vapor provocaron que los primeros siguiesen controlando la mayor parte de la navegación mundial. Una vez superados esos problemas marginales de oferta, a partir de mediados de los ochenta, la generalización del vapor fue mucho más rápida ${ }^{4}$ Independientemente de los presupuestos teóricos de cada uno, todos ellos aceptan que el vapor se fue introduciendo primero en las rutas cortas - la navegación de cabotaje y la efectuada entre puertos europeos-y sólo tras la adopción del motor compuesto y, especialmente del motor de triple expansión, el vapor pudo competir eficazmente en las rutas oceánicas. Sin embargo, el proceso de difusión del vapor en las principales flotas mercantes del mundo estuvo lejos de ser uniforme, lo que indica que en el mismo intervinieron otros factores además de los cambios en los costes relativos de producción, fundamentalmente la estrategia empresarial y el contexto institucional en el que ese proceso se desarrolla ${ }^{5}$.

A la altura de 1870 la difusión del vapor en las principales flotas mercantes del mundo era casi testimonial: sólo cinco países tenían un tonelaje de vapor que representaba más del 10 por 100 del tonelaje total de sus respectivas flotas. La apertura del canal de Suez en 1869 significó la irrupción en los mercados del este asiático de la navegación a vapor y aceleró el cambio del motor de un cilindro al motor compuesto durante los años $70^{\circ}$. En 1880 ya eran nueve los países, cuyo tonelaje de vapor suponía más del 10 por 100 del total, tonelaje que todavía era mayoritariamente empleado en las rutas comerciales del Atlántico Norte ${ }^{7}$. La reducción del consumo y del espacio reservado al carbón gracias a la generalización del motor compuesto y a la

\footnotetext{
4 Rosenberg (1979), pp. 208-27.

5 Rosenberg (1979), p. 230; Broeze (1989), p. 1.

6 Fletcher (1958), pp. 557-63.

7 Fischer y Nordvik (1986), p. 530.
} 
aplicación del de triple expansión provocó un crecimiento muy importante del tonelaje de vapor durante los años ochenta. Para 1890 la mayor parte de las flotas habían duplicado o triplicado sus porcentajes. Bélgica, Gran Bretaña, Alemania, Francia y España poseían ya flotas compuestas predominantemente por vapores. En 1910 la difusión del vapor estaba generalizada en la mayor parte de las flotas, con la excepción de Canadá y Finlandia ${ }^{8}$.

En España, la navegación a vapor se difundió en la primera mitad del siglo XIX por las aguas del Mediterráneo, dedicada al transporte de pasajeros. A partir de los años sesenta el vapor se extendió por las aguas del Atlántico norte, integrando también el transporte de mercancías 9 . La difusión de la nueva tecnoiogía en la flota mercante española se realizó con una relativa rapidez desde una perspectiva internacional: entre 1870 y 1890 ésta se encontraba entre las cinco primeras atendiendo al grado de difusión del vapor, presentando una evolución similar a la de la flota británica. El crecimiento más importante se produjo durante los años ochenta y noventa: de tener un 18 por 100 de su tonelaje compuesto por vapores en 1880 , éstos representaron un 60 por 100 en 1890 y un 83 por 100 diez años más tarde. En 1900 España era el país que contaba con un mayor porcentaje de vapores en su flota mercante, sólo superado por Bélgica ${ }^{10}$. Parece pues que, aun careciendo de una moderna industria de construcción naval, la flota española no sólo no permaneció al margen del proceso de modernización tecnológica que se estaba produciendo en la navegación mundial, sino que se convirtió en una de las pautadoras de éste a través de la adquisición de buques modernos a los astilleros o a los navieros británicos ${ }^{11}$.

La próspera imagen internacional de la flota mercante española contrasta con la visión que de la transición de la vela al vapor han ofrecido los escasos trabajos que sobre esta cuestión se han realizado en España. El trabajo de Carrera Pujal (1961), construido a partir del Archivo de la Junta de Comercio de Barcelona, rellenaba con abundantes datos una vieja tesis de los navieros catalanes que atribuian su decadencia a la abolición del Derecho Diferencial de Bandera en 1868, y que después fue suscrita por otros autores como Estasén en 1880 o Sánchez de Toca en 1898. Tres años antes Vicens Vives y Llorens ofrecian en apenas cinco páginas una visión muy diferente de la

8 Todos los porcentajes han sido tomados de Fischer y Nordvik (1986), Tabla IV, p. 531 Sobre Finlandia, véase Kaukianien (1980). Sobre Canadá, véase Fischer y Sager (1986) y Sager y Panting (1985).

9 Nadal (1988).

10 Porcentajes obtenidos de Fischer y Nordvik (1986), Tabla IV, p. 531

11 Sobre la industria naval en España, véase Gómez Mendoza (1988). 
marina mercante catalana en la segunda mitad del ochocientos. Para estos últimos, la decadencia de la flota mercante de vela catalana se inició antes de la abolición del derecho diferencial de bandera y fue provocada por la introducción del vapor y del negocio marítimo moderno. Los navieros catalanes conocian el buque de vapor, pero la falta de capitales y de mercados - -y no la supresión del derecho diferencial- fueron los factores que impidieron su desarrollo. La pérdida de las colonias en 1898 sería la «última puñalada» a la flota catalana, mientras que en esas mismas fechas la flota vizcaína pasaba a ostentar la hegemonía del tonelaje mercante español gracias al transporte del hierro y el carbón, a la capitalización de los beneficios mineros y al establecimiento de una industria pesada ${ }^{12}$. Los trabajos que aparecieron en las décadas siguientes sobre la flota bilbaina o españőla vinieron a corroborar esa imagen dibujada por el maestro catalán ${ }^{13}$. Sin embargo, en los últimos años una serie de autores han adelantado el origen de la flota mercante de vapor vasca, matizando aquella interpretación y señalando otros factores para su surgimiento ${ }^{14}$.

La contrastación de estas teorías hace necesario reconstruir la evolución de la flota mercante española durante la segunda mitad del siglo XIX, analizar los aspectos del cambio estructural que este sector experimenta y las actitudes de los navieros respecto a cada uno de ellos. En España el proceso de difusión de la nueva tecnología se inicia en el marco de una reforma arancelaria y de una profunda reestructuración de la marina mercante española durante los años setenta. Es precisamente este cambio institucional el que va a acelerar el ritmo del cambio técnico. La estrecha relación entre los intereses del transporte marítimo y los del comercio (la mayor parte de los armadores eran también comerciantes) determinó las actitudes y los comportamientos de los empresarios navieros, especialmente en la discusión de la reforma arancelaria, donde comercio y marina mercante aparecen como intereses contrapuestos. La estrategia empresarial y el marco institucional se revelan como factores tan poderosos para explicar el ritmo y la dirección del cambio técnico como los costes relativos de cada clase de navegación.

12 Vicens Vives y Llorens (1958), pp. 91-93.

13 Véase Roldán y García Delgado (1973) y González Portilla (1981).

14 Fernández de Pinedo (1988), Torres (1991) y Valdaliso (1989) y (1991a). 


\section{LOS CAMBIOS EN EL MARCO INSTITUCIONAL Y LA DIFUSION DE LA NUEVA TECNOLOGIA}

Contrariamente a lo que sucedía en el otro sector de capital social fijo de la economia española a mediados del siglo xIX, el ferrocarril, la marina mercante tenía una legislación completamente obsoleta en comparación al proceso de desarrollo capitalista que estaba teniendo lugar en España. Antes de la reforma liberal de 1868 el transporte marítimo arrastraba consigo una gran cantidad de rémoras jurídicas del pasado. Por una parte, su régimen fiscal y administrativo era extremadamente complejo, dificultando la navegación. Las quejas de los navieros y los organismos provinciales consultados con motivo de la información arancelaria de 1867 son muy expresivas al respecto. La Comisión de Navieros del Círculo Mercantil de Barcelona señalaba entre las principales trabas que impedían el desarrollo de la marina mercante en España «los crecidos impuestos de sanidad y consumo..., las infinitas contribuciones que bajo diferentes conceptos gravitan sobre la marina mercante, haciéndola la industria más perjudicada de España..., la complicada legislación de aduanas..., los derechos superiores a los de otra nación alguna que se pagan a los cónsules españoles en el extranjero... [y] las infinitas exacciones y abusos a que da lugar la complicada tramitación para el despacho de los buques» ${ }^{15}$. El propio cónsul inglés en Cádiz comentaba en 1864 que

Las leyes de navegación de España, que todavía siguen en vigor, son rígidas y protectoras. Los bienes importados bajo la bandera española están sujetos a un derecho mucho más moderado que los importados en naves extranjeras; pero existen tantos gravámenes en contra que se imponen sobre el naviero español en forma de gabelas, derechos de matrícula, etc. (como una especie de contrapartida por su protección) que no es improbable que él casi preferiría que las leyes de navegación no le estorbasen con sus nominales y embarazosos beneficios ${ }^{16}$.

Por otra, el factor trabajo no era una mercancía libre, sino que estaba sometido a una serie de condicionantes y restricciones estipuladas en las Ordenanzas de Matrículas de Mar de 1802. El objetivo de las matrículas de mar era el de tener individuos suficientes para tripular los buques de la Armada. A cambio, reservaban a éstos la navegación, pesca e industrias

15 Información (1867), t. I, p. 90. De forma análoga se expresan la Junta de Agricultura, Comercio e Industria de Barcelona y la de Santander.

16 Parliamentary Papers (PP), Commercial Reports, Cádiz, 1865, LIII, p. 87 (traducción mía, J. V.). 
marítimas. Aunque en 1859 se había permitido que los trabajos de carga y descarga en los puertos pudieran ser efectuados por personal no matriculado $\mathrm{y}$, cinco años más tarde, se abolieron definitivamente los gremios de mar, la pervivencia de las matrículas de mar y la obligación de llevar un número estipulado de marineros, muy superior al de otros pabellones, repercutía gravemente sobre el coste total de la explotación del buque ${ }^{17}$. Sánchez de Toca indicaba a finales de siglo que «por no tener esta traba otros pabellones... navegando con menos gente, hallan tripulaciones de muy menor coste en salarios y mantenimiento de la tripulación» ${ }^{18}$. Además, la marina mercante carecía de mano de obra cualificada para las nuevas tecnologías que se empezaban a introducir en los buques ${ }^{19}$. La reforma de 1868 solucionó algunos problemas, pero no modificó la estructura organizativa de un sector que todavía seguía dependiendo del Ministerio de Marina.

A estas trabas institucionales se unía una política arancelaria de protección a la industria naval que prohibía la importación de buques extranjeros en España. En un primer momento, confiando en que la industria nacional pudiera satisfacer la demanda de la marina mercante, se prohibió en 1837 la compra y matriculación de buques extranjeros, permitiendo, en cambio, la libre introducción de maquinaria para los buques de vapor. Ante el fuerte atraso técnico de la industria naval, los aranceles de 1841 y 1849 decretaron la libre introducción de buques extranjeros a cambio de unos elevados derechos arancelarios ${ }^{20}$. Los constructores recibieron, en compensación, una prima de 30 pesetas por tonelada botada al agua, vigente hasta 1865.

Equipada con buques caros y antiguos, sometida a una multiplicidad de impuestos y con unos costes salariales elevados, la flota mercante española estaba protegida gracias a un derecho diferencial de bandera sobre las mercancías importadas que, aproximadamente, suponia un recargo del 20 por 100 en los derechos de aduana sobre el valor de los productos introducidos en pabellón extranjero ${ }^{21}$. A pesar de esta sensible protección, una creciente parte del comercio exterior español era transportado por buques extranjeros. La flota mercante española era doblemente insuficiente para satisfacer la demanda derivada de transporte que el comercio exterior de España generaba: ni

17 Sobre las matrículas de mar y el problema de la mano de obra en los buques, véase Valdaliso (1991a).

18 Sánchez de Toca (1986), p. 231.

19 Valdaliso (1991a).

20 El Arancel de 1841 permitió la introducción de buques de hierro de mäs de 400 toneladas. El de 1849 extendió ese permiso a todos los buques de hierro y a lós de madera de más de 400 toneladas. Véase Alzola (1894), p. 304.

21 Véase Valdaliso (1991a). 
por su capacidad de transporte ni por los precios que podía ofertar eta capaz de competir con otras flotas extranjeras. Incluso un autor al que le era tan caro el derecho diferencial como Sánchez de Toca, reconocía a finales del siglo pasado que la marina mercante hispana, como consecuencia del cambio técnico y el descenso de los fletes, «apenas promediado el siglo, difícilmente podía mantener la competencia hasta bajo el resguardo del régimen diferencial» ${ }^{22}$. La bandera nacional que en los años 1850-54 transportaba el 47 por 100 del comercio exterior de España vio reducida su participación en el mismo a un 31 por 100 en $1855-59$ y a un 24 por 100 en $1860-64$ (véase cuadro 6).

La competencia de las naves extranjeras era superior en aquellas mercancías de mucho peso y poco valor, que son las que proporcionan la mayor demanda de tonelaje. La protección, al establecerse sobre el valor de las mercancias, apenas repercutía sobre bienes cuyo precio era muy pequeño en relación a su unidad de peso y en los que el flete suponía una gran parte del precio final. La Sociedad Económica Matritense señalaba que, «a pesar del derecho diferencial, la mayor parte de nuestro comercio se hace en buques extranjeros» ${ }^{23}$. La Junta de Agricultura, Industria y Comercio de Viqcaya reconocía en 1866 que:

Los buques nacionales se dedican poco o nada al transporte de carbón mineral, madera, material para ferrocarriles, etc., por ser el derecho diferencial de poca importancia, pues además de estar los buques extranjeros en mejor situación para navegar, se hallan más a mano en los puntos productores para su embarque, y hay entre ellos apropiados para conducir aquellas mercancías. En sus actuales circunstancias, los buques españoles sólo pueden competir con ventaja sobre los extranjeros en el transporte de bacalao, géneros coloniales, especias, tejidos, quincalla, etc., cuyos derechos diferenciales de bandera permiten que el transporte de estos géneros desde los puertos de Europa lo hagan casi exclusivamente los vapores españoles ${ }^{24}$.

Que la flota mercante española era a todas luces incapaz de satisfacer la demanda de transporte generada por el todavía exiguo comercio exterior español era un hecho imposible de negar por la práctica totalidad de los individuos y organismos consultados en la información de 1867. El secretario de la delegación británica en España advertía en 1866 que «a menos que se

22 Sánchez de Toca (1986), p. 171. Jimeno (1889), pp. 8-9, coincide en señalat la escasa protección que el Derecho Diferencial de Bandera ofrecía a la flota española.

23 Información (1867), t. I, p. 140.

24 Información (1867), t. I, p. 127. Una opinión similar era la de la Junta de Agricultura, Comercio e Industria de Barcelona, ibidem, p. 91. 
produzca un cambio en el sistema, es seguro que pronto la flota mercante española se verá obligada a contentarse con el tráfico de cabotaje» ${ }^{25}$. De ahí que nadie se opusiera frontalmente a la supresión del derecho diferencial, puesto que con él la navegación española ya estaba reducida a determinados tráficos que empleaban muy poco tonelaje. El objetivo de los navieros, como veremos más adelante, fue conseguir una reforma en profundidad de la legislación española que permitiera al pabellón nacional competir eficazmente con los extranjeros 26 .

Esa estrategia de la mayor parte de los navieros españoles se inscribía en una coyuntura liberalizadora de la economía española. Tras la crisis de 1864 se inicia un período de revisión del sistema proteccionista anterior que culminará en la entrada de la escuela economista liberal en el gobierno a partir de $1868^{27}$. Pocos días después de la firma del Tratado de Comercio con Francia la ley del 21 de julio autorizaba la supresión del derecho diferencial sobre las mercancías importadas por tierra de Francia y Portugal, la abolición del derecho diferencial de bandera sobre las mercancías europeas, la supresión de las trabas y gravámenes de todo tipo que pesaban sobre la marina mercante y la reducción de los derechos arancelarios sobre las primeras materias empleadas en la construcción de buques. Por real decreto de 10-XI-1865 se nombró una comisión encargada de concretar el procedimiento para llevar a cabo aquellas medidas ${ }^{28}$.

La coyuntura de la segunda mitad de los sesenta va a determinat definitivamente la estrategia de los navieros españoles. El desarrollo del ferrocarril en España permitió hacer efectiva la posibilidad de desviar las mercancías a otros puertos extranjeros donde el precio del transporte fuese inferior. Santander y, sobre todo, Bilbao van a ser los puertos más afectados. La reducción de tarifas ferroviarias of recidas conjuntamente por la Compañia de Ferrocarriles del Norte de España y la del sur de Francia a partir de 1865 consiguió desviar el tráfico de mercancias, anteriormente dirigido a Bilbao, hacia Burdeos, absorbiendo una gran cantidad de tráfico de carga de la línea Bilbao-Tudela ${ }^{29}$. Al año siguiente, el Tratado de Comercio entre Francia y

25 PP, Reports, LXXII, 1866, p. 379 (traducción mía, J. V.).

26 Los debates de la información oral son muy explicitos en este punto. La mayor parte de los navieros aceptaban una abolición gradual del derecho diferencial a cambio de la reforma del régimen fiscal y administrativo. Véase Información (1867), I, pp. 243-254.

27 Véase Costas (1988), p. 34.

${ }^{28}$ Costas (1988), pp. 1516.

29 Véase PP, Commercial Reports, 1866, LXX, pp. 481-482. La Compañia del ferrocarril de Bilbao a Tudela habia sido creada en 1858 por comerciantes bilbainos-residentes en esta ciudad o en La Habana - interesados en unir el interior cerealicola y vitivinicola con el puerto de Bilbao y 
España que disponía que las mercancías francesas que penetrasen en España por tierra serían admitidas en los mismos términos que si fuesen transportadas en bandera española por mar, reforzó la competitividad del ferrocarril sobre el transporte marítimo. De hecho, las compañias ferroviarias rebajaron aún más las tarifas de conducción, especialmente en los puntos de cruce con líneas dirigidas a la costa. El resultado fue espectacular: ese mismo año las 9/10 partes de las importaciones francesas que entraban antes en España a través de Bilbao lo hicieron por ferrocarril vía Irún ${ }^{30}$. El cónsul inglés en Bilbao señalaba en 1866 que

La consecuencia ha sido que los ferrocarriles a los que antes me he referido, ayudados por esta inmensa ventaja sobre los puertos y, además, adoptando una complicada e irregular tarifa que hace la competencia imposible a las líneas que se dirigen a la costa, no sólo transportan a Burdeos para su embarque grandes cantidades de trigo y harina de Castilla, sino que también han monopolizado prácticamente todo el comercio entre Francia y España, con el serio perjuicio de éste y otros puertos españoles» ${ }^{31}$.

Ante esta amenaza evidente al futuro de Bilbao como plaza comercial, la reacción de los navieros vascos, al igual que los de Santander, consistió en salvaguardar preferentemente sus intereses comerciales. Los comerciantes navieros bilbaínos apoyaron la abolición del derecho diferencial de bandera y de las múltiples cargas que pesaban sobre el sector, y solicitaron además la revisión de la ley de ferrocarriles al objeto de establecer una tarifa uniforme para todas las líneas ${ }^{32}$. De esta forma, aunque quedaban desprotegidos frente a la competencia extranjera en el mercado de transporte, se podía recuperar la competitividad del transporte marítimo frente al ferroviario $y$, lo que era más importante, la competitividad del puerto de Bilbao frente a otros puertos extranjeros.

La Junta de Comercio de Barcelona, en cuanto percibe que la abolición es un

consolidar la función redistribuidora de este puerto frente al de Santander. Entre los socios de este compañía se encuentran los principales armadores bilbainos (Olaguíbel, Abaitua, Urigüen), todos ellos vinculados al comercio con las Antillas. Sobre esto, véase PP, 1862, LVII, pp. 170-73; Fernández de Pinedo (1986), pp. 32-34.

30 PP, Commercial Reports, 1867/8, LXVIII, p. 86.

31 Ibídem, p. 87 (traducción mía, J. V.). En 1879 la Junta de Agricultura, Industria y Comercio de Vizcaya señalaba lo mismo; véase Información (1879), t. I, p. 390. También en 1866 la Junta de Agricultura, Industria y Comercio de Barcelona se quejaba de la competencia del ferrocarril, protegido a expensas de la marina mercante, según esta institución; véase Información (1867), t. I, p. 125.

32 Asi lo indicaba el cónsul inglés en Bilbao. PP, Commercial Reports, 1867/8, LXVIII, p. 87. 
hecho inevitable, recomienda «que se pida con ese motivo la remoción de los grandes gravámenes y obstáculos que afligen a la marina, supuesto que a su modo de ver hay disposición a reconocer semejante petición” ${ }^{33}$. Las Juntas de Bilbao y La Coruña apoyaron a la de Barcelona. La de Santander, claramente partidaria de la abolición, mantendrá la misma actitud: tras conocer la intención del gobierno de suprimir el derecho diferencial de bandera, envió al ministro de Hacienda un extenso memorial sobre las trabas que, a su juicio, impedian el desarrollo de la flota mercante ${ }^{34}$. La comisión de navieros del Circulo Mercantil de Barcelona indicaba en 1866 que

La supresión del derecho diferencial de bandera hoy, en el precario estado en que se halla la marina mercante, traerá la completa ruina de los navieros españoles. Unicamente destruyendo la institución de las matrículas de mär y todas las consecuencias de las mismas..., suprimiendo todas cuantas trabas $\mathrm{e}$ impuestos se cobran hoy de la marina mercante, dentro y fuera de España ... e imponiendo a la misma una contribución única ... y armonizando con los principios de igualdad de bandera todos los demás ramos de la administración, entonces podrá el Gobierno concederla, pero sólo a las naciones que abran sus puertos con la recíproca a nuestros productos y buques. Exceptuando siempre y en absoluto el comercio de cabotaje ${ }^{35}$.

El 22 de noviembre de 1868 el ministro de Hacienda, Laureano Figuerola, promulgaba dos decretos en los que se contenía la reforma del sector. El primero suprimía el derecho diferencial de bandera, reservando el cabotaje y la navegación con las colonias para el pabellón nacional. La supresión se llevaria a cabo de forma gradual hasta convertirse en definitiva a partir de $1872^{36}$. El segundo permitió la introducción en España de buques de todas las clases (art. $1 .^{\circ}$ ), autorizó al armador para fijar el número de tripulantes que podía llevar en su nave (art. 5. ) y redujo todos los impuestos a uno solo, cobrado sobre las toneladas descargadas en puerto (art. 6..$^{\circ}$. Los constructores, además de la protección conferida por los derechos arancelarios y las primas a la construcción, gozarían de franquicia para la importación de materiales destinados a la construcción de buques (arts. 13 y 14) ${ }^{37}$.

\footnotetext{
33 Carrera Pujal (1961), p. 91.

34 Información... (1867), t. I, p. 99.

35 Información... (1867), t. I, pp. 90-91. La Junta de Agricultura, Industria y Comercio de Santander scñala lo mismo: «Si el derecho diferencial de bandera se suprimiese sin plantear simultáneamente las reformas precisadas al contestar a la pregunta $6 .^{\mathrm{a}}$, los navieros españoles quedarían completamente arruinados, porque el comercio todo de Europa, y aun el de altura, lo absorberian las naves extranjeras", ibidem, p. 100.

36 Costas (1988), p. 89.

37 Martínez Alcubilla (1923), t. I, pp. 37-38.
} 
La liberalización del sector y el aumento de la competencia fue el detonante para la modernización de la flota española, efectuada a través de la compra de buques de hierro a vapor en Gran Bretaña. En 1883, de los 407 buques de vapor mayores de 50 toneladas que poseía la matrícula española, 341 habian sido construidos en aquel país por tan sólo 22 en España ${ }^{38}$. Los efectos hacia atrás del desarrollo de la marina mercante--demanda dirigida a la siderurgia y a la industria naval - fueron absorbidos por las industrias y los astilleros británicos, no por los españoles. El fuerte atraso de estos sectores en España igualó a cero el coste de oportunidad de adquirir buques en el extranjero para el armador hispano, aun a pesar de los elevados derechos arancelarios que tenía que satisfacer por ellos. La abolición completa del derecho diferencial a partir de 1872 facilitó la competencia de las flotas extranjeras en el transporte de mercancías hasta entonces reservadas al pabellón hispano y unificó el mercado de fletes que, a partir de ahora, sería fijado por el coste de explotación de los buques extranjeros, muy inferior al de los buques españoles. La bandera extranjera, que ya controlaba la mayor parte del comercio exterior español, incrementó su participación en el mismo. Ante esta situación, la disyuntiva de los navieros españoles fue la de tener buques modernos -importados- con lo que poder competir, o desaparecer.

A partir de los años setenta se produce un fuerte aumento en las importaciones de buques que alcanzará su cúspide en los primeros años de la década de los $80^{39}$. La flota mercante española, que hasta 1867 apenas había sufrido cambios significativos, conoce desde finales de esa década y durante toda la siguiente coyunturas de muy variado signo: aumento desde 1870 hasta 1873, descenso desde 1873 hasta 1879 y nuevo crecimiento a partir de entonces. El crecimiento de la flota de vapores se intensifica durante los períodos 1868-73, 1879-84 y desde 1890 en adelante. El estancamiento del vapor entre 1874 y 1878 no es un fenómeno particular de España. Se enmarca en la depresión de mediados de los setenta que tiene lugar en la navegación mundial y que también acelera la deçadencia de los veleros en nuestro país ${ }^{40}$. Desde 1879 el tonelaje de vapor es él responsable del crecimiento de la flota mercante española, superando por primera vez al de vela en 1883. Paralelamente, desde 1872, la flota de veleros sufre un acusado descenso hasta 1888, estacionándose a partir de ese año en torno a las 200.000 toneladas. Así pues, la introducción de vapores en la matrícula española se produce de forma

\footnotetext{
38 Alzola (1886), p. 389.

39 Véase Valdaliso (1911a).

40 Sobre la crisis de mediados de los 70, véase Angier (1920) en 1874, FP, 22-I-1920, p. 370; Matthews (1979), p. 233.
} 
simultánea a la disminución de buques de vela. Aunque la difusión del vapor se generaliza en los años ochenta, lo ocurrido en la década anterior resulta especialmente significativo para comprender la dirección final y la evolución posterior de este proceso.

\section{GRAFICO 1}

Tonelaje de la flota mercante española, 1860-1895

TRB

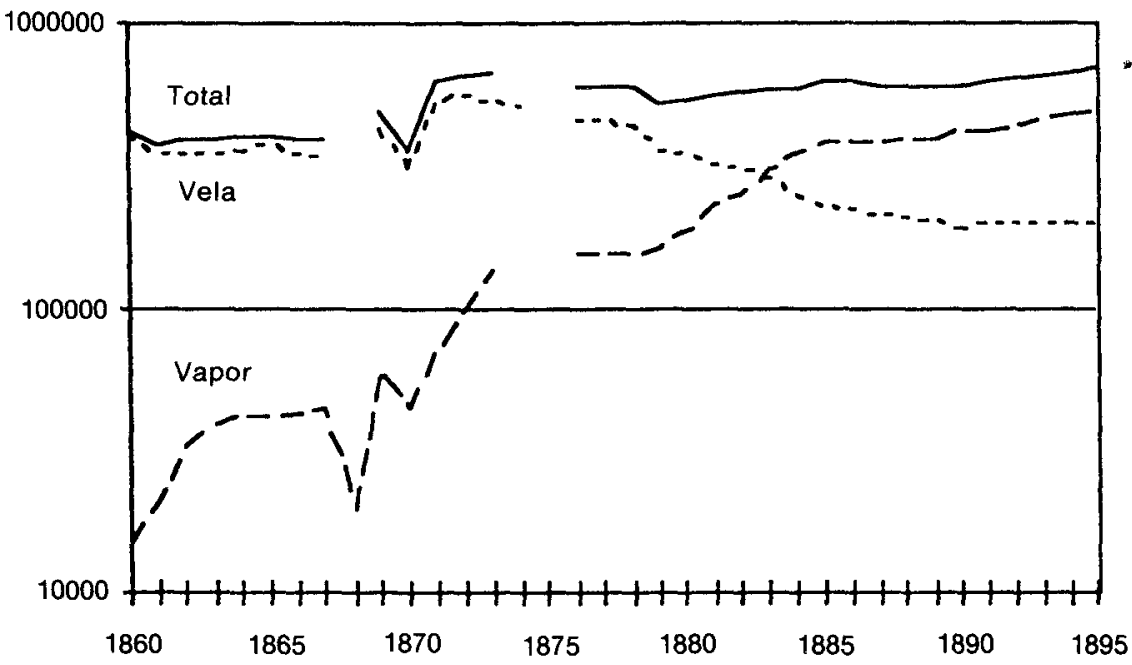

FUENTE: Valdaliso (1991), A. 1A. Buques $>50$ TRB.

Esos datos generales nos muestran la cronología y el ritmo del cambio técnico en la flota española, pero, sin embargo, no aclaran completamente el fenómeno. Entre 1859 y 1833 dispongo de las altas y bajas de buques efectuadas en las matrículas de Bilbao y Barcelona. La documentación indica, además, el tipo de buque, la navegación en la que estaba empleado y la causa de la baja, entre otros datos. A pesar de su desigual calidad, especialmente en el último quinquenio, ofrecen una información, a mi juicio, destacable, no sólo sobre la cronología, sino también sobre las características del proceso de cambio técnico en las dos principales matrículas de la flota mercante española.

En Bilbao, las adquisiciones de vapores a Gran Bretaña y Francia comienzan ya a finales de los años cincuenta. Como Graham ha señalado para 
la navegación mundial ${ }^{41}$, los buques de vapor se introdujeron primero en las rutas cortas - navegación con Europa y cabotaje-- en 1862, según los datos del cónsul inglés en Bilbao, los vapores que circulaban por ese puerto estaban empleados en la navegación de cabotaje o, a lo sumo, en el tráfico con Inglaterra y Holanda. Mientras tanto, los veleros dominaban totalmente la navegación con América ${ }^{42}$. El inicio de esta temprana transición de la vela al vapor arruinó la industria de construcción naval que estaba localizada en la ría del Nervión. El atraso técnico y la inversión en otros sectores más rentables como el comercio o el ferrocarril fueron las principales causas de su decadencia ${ }^{43}$. Salvo algunas excepciones, la práctica totalidad de los buques de vapor adquiridos por los navieros de Vizcaya fueron importados. La demanda de veleros, por el contrario, continuó siendo satisfecha por los astilleros de la ría bilbaína. Según los datos de la Lista Oficial de Buques de 1884, el 95 por 100 del tonelaje de vapor matriculado en Bilbao había sido comprado en el Reino Unido, siendo un 24 por 100 de segunda mano; el tonelaje de vela era mayoritariamente de construcción española - - un 64 por 100--, sobre todo de Bilbao, donde se había construido el 82 por 100 del tonelaje nacional.

El predominio del vapor en la inscripción de nuevos buques en la flota bilbaína comienza en la segunda mitad de la década de los setenta. En los primeros ochenta las diferencias se amplian debido a un acusado descenso de la flota de vela de altura, que había estado sometida a un proceso de constante renovación en las décadas anteriores ${ }^{44}$. El vapor inició su despegue autónomo a partir de la liberalización del sector en 1868. Desde entonces, y hasta 1873-74, la mayoría del tonelaje adquirido se empleó en la navegación con Europa. A partir de la segunda mitad de los setenta, los navieros bilbainos vendieron una parte importante de su flota de veleros de altura al extranjero y compraron nuevos vapores, muchos de ellos ya destinados al tráfico con América ${ }^{45}$.

41 Graham (1956), pp. 81-83.

42 PP, Commercial Reports, 1863, LXX, p. 409. Sobre la difusión del vapor en los tráficos donde estaban empleados los buques españoles, véase Valdaliso (1991a).

43 El cónsul Young indicaba acertadamente que "puesto que el comercio general de Bilbao está aumentando, esto [el declive de la industria naval] sólo puede ser explicado por la introducción del vapor y el empleo del capital en inversiones más rentables», PP, 1862, LVIII, p. 169 (traducción mía, J. V.).

44 Entre 1859 a 1874 el saldo neto total de veleros de altura en la matrícula de Bilbao fue de 53 buques con 14.000 toneladas de arqueo (fuente: véase cuadro 1).

45 Más del 50 por 100 de las bajas en la matrícula de veleros en el período 1879-1883 se debieron a su venta a extranjeros (fuente: véase cuadro 1). 


\section{CUADRO 1}

Saldos netos del tonelaje mercante registrado en Bilbao por quinquenios $y$ destino de navegación, 1859-1883*

\begin{tabular}{|c|c|c|c|c|c|c|c|c|}
\hline \multirow[b]{2}{*}{ Años\# } & \multicolumn{2}{|c|}{ Cabotaje } & \multicolumn{2}{|c|}{ Nav. Europa } & \multicolumn{2}{|c|}{ Nav. de altura } & \multicolumn{2}{|c|}{ Totales } \\
\hline & Vapor & Vela & Vapor & Vela & Vapor & Vela & Vapor & Vela \\
\hline $1859-1864$ & 180 & 636 & 510 & -2.151 & 157 & 3.591 & 847 & 2.076 \\
\hline $1864-1869$ & - & 一 & 154 & 4.657 & - & 7.687 & 154 & 12.344 \\
\hline $1869-1874$ & 79 & - & 5.883 & 7.527 & 1.937 & 2.747 & 7.899 & 10.274 \\
\hline 1874-1879† & 160 & - & 3.867 & 1.544 & 6.231 & 1.900 & 10.258 & 3.444 \\
\hline 1879-1883 $\ldots \ldots \ldots \ldots$ & -17 & -157 & 1.393 & - & 7.894 & -12.821 & 9.270 & -12.978 \\
\hline Total & 402 & 479 & 11.807 & 11.577 & 16.219 & 3.104 & 28.428 & 15.160 \\
\hline
\end{tabular}

FUENTE: Elaboración propia a partir de Archivo General de Marina Alvaro de Bazán, Sección Navegación Mercantil Altas y Bajas de buques, varios legajos (sin catalogar en el momento de recoger la documentación).

* Cifras expresadas en toneladas de arqueo neto.

\# De 1 de julio a 30 de junio.

t Para el año $1878 / 79$ no contamos con el destino de las altas y bajas de los buques.

En Barcelona comienzan a introducirse vapores a mediados de los sesenta, destinados fundamentalmente a la navegación de altura. Al igual que en Bilbao, el proceso se acelera en la segunda mitad de los 70 y en los primeros ochenta. De manera similar, la flota de vela conoce un acusado declive en el período 1879-83.

En lineas generales, el comportamiento de los navieros vascos y catalanes no difiere sustancialmente del mantenido por el resto de navieros españoles. Ambos grupos incrementan sus inversiones en buques modernos de vapor a partir de la segunda mitad de los años setenta y en los primeros años ochenta, buques que van a emplear preferentemente en la navegación con América. El resultado global del período supone un incremento en la flota de vapores de aproximadamente 300.000 toneladas de arqueo neto en cada matrícula. Al mismo tiempo, ese proceso se ve acompañado de la liquidación de una parte importante de la flota de veleros de altura que, en el caso de los navieros vascos, fueron vendidos al extranjero. Los informes de los armadores gaditanos en la comisión arancelaria de 1878 son unánimes en señalar el mismo hecho en su matrícula ${ }^{46}$. Una parte de los armadores españoles, aquellos con

46 «Nuestra misma matrícula, que el año de 1868 tenia 73 buques de altuta, no cuenta hoy más que 20, que sus armadores los cedieron por el 25 por 100 de su valor, por no tener fletes para hacerles producir», Información... (1879), t. I, p. 361. 


\section{CUADRO 2}

Saldos netos del tonelaje mercante registrado en Barcelona por quinquenios $y$ destino de navegación, 1859-1883*

\begin{tabular}{|c|c|c|c|c|c|c|c|c|}
\hline \multirow[b]{2}{*}{ Años\# } & \multicolumn{2}{|c|}{ Cabotaje } & \multicolumn{2}{|c|}{ Nav. Europa } & \multicolumn{2}{|c|}{ Nav. de altura } & \multicolumn{2}{|c|}{ Totales } \\
\hline & Vapor & Vela & Vapor & Vela & Vapor & Vela & Vapor & Vela \\
\hline $1859-1864$ & -162 & 100 & -1.043 & -- & 916 & 2.342 & -289 & 2.442 \\
\hline $1864-1869$ & 1.599 & 479 & 985 & - & 4.009 & 8.789 & 6.593 & 9.268 \\
\hline $1869-1874$ & -333 & -340 & 22 & $-\cdots$ & 6.902 & 17.836 & 6.591 & 17.496 \\
\hline $1874-1879 \ldots$ & 198 & -401 & 5.916 & - & 5.307 & -92 & 11.421 & -493 \\
\hline $1879-1883 \dagger$ & & & & & & & 8.259 & -14.157 \\
\hline Total & 1.302 & -162 & 5.880 & - & 17.134 & 28.875 & 32.575 & 14.556 \\
\hline
\end{tabular}

FUENTE: Elaboración propia a partir de Archivo General de Marina Alvaro de Bazán, Sección Navegación Mercantil Altas y Bajas de buques, legajos 7149-51, 7153-54, 7159, 7162 y

7165; Sección Estadística, Navegación y Pesca, Legajos 2360 y 2364.

* Cifras expresadas en toneladas de arqueo neto.

\# De 1 de julio a 30 de junio.

† En esta etapa no contamos con el destino de las altas y bajas de los buques. Además las cifras se refieren solamente al segundo semestre de 1879 y a los años $1881 / 82$ y 1882/83.

fuertes intereses en la navegación a vela, interpretaron este hecho como una consecuencia más o menos directa de la abolición del derecho diferencial de bandera:

La supresión del derecho diferencial de bandera es, sin duda, entre otras causas, la que más ha contribuido a la casi total ruina en que hoy se halla nuestra marina mercante, y que los extranjeros aprovechan para hacer a la navegación española una ventajosa competencia en la mayor parte de nuestros mercados. Numerosos datos podrían aducirse en comprobación de esta verdad, pero basta sólo para convencerse de ella, la rápida disminución que desde la fecha del decreto de supresión ha tomado el número de buques españoles que se dedican a la navegación de altura. Nadie se atreve ya a emplear sus capitales en esta industria, necesario auxiliar del comercio y uno de los principales elementos de prosperidad y riqueza para una nación; asi es que puede decirse que desde entonces ni un sólo buque se ha construido en España destinado a recorrer los mares de Asia y América, que pocos años ha cruzaban en todas direcciones nuestra bandera, y por el contrario, faltos los armadores españoles de recursos para sostener los que tenían, pues que a más de las numerosas gabelas y crecidos impuestos que pesan sobre nuestra marina, el derecho diferencial suprimido, no pueden obtener ya los tipos de fletes necesarios para 
su negocio, pues que los extranjeros pueden hacerlo a precios mucho más reducidos; se han apresurado a vender casi todos sus buques a los ingleses ${ }^{47}$.

Sin la protección del derecho diferencial, la mayor parte del tonelaje de vela español no pudo resistir la competencia de veleros o vapores extranjeros. Como vimos en el gráfico 1 , a partir de 1872 , momento en el que se suprimen completamente las tarifas diferenciales, el tonelaje de vela comenzó a caer de forma sostenida en el registro español. La caída de los fletes en los mercados internacionales desde mediados de esta década y las mejoras introducidas en los buques de vapor que les permiten desplazar a los veleros de la navegación entre Europa y América agravaron aún más la situación del buque de vela. Una parte de los armadores españoles se desprendieron del mismo adquirien-, do en su lugar modernos vapores construidos en el extranjero. El resto permaneció aferrado a la vieja tecnología o simplemente acabó liquidando su flota. Los cambios en el marco institucional, en los mercados internacionales y en la nueva tecnología aceleraron el ritmo de difusión del buque de vapor en la flota española durante los años setenta. La rapidez del proceso - en 1883 el tonelaje de vapor ya había superado al de vela-- hizo que el ajuste fuera más dramático.

Una de las consecuencias de esta profunda renovación tecnológica de la flota española fue el rejuvenecimiento de su tonelaje. Los armadores españoles compraton buques en el extranjero, sobre todo en el Reino Unido, nuevos o de pocos años de edad. Según los datos de la Lista Oficial de Buques de 1886, sólo un 38 por 100 del tonelaje era de segunda mano, el resto era de nueva construcción ${ }^{48}$. A finales de 1885 un 40 por 100 del tonelaje de vapor abanderado en España tenía entre 0 y 5 años, mientras que sólo un 10 por 100 superaba los 20 años de edad.

El cuadro 4 muestra la estructura de la moderna flota de vapor de España por matrículas. Destacan especialmente dos: las de Barcelona (29,6 por 100) y Bilbao (24,1 por 100). Tras ellas, con unos porcentajes similares que oscilan entre el 6 y el 7 por 100, se encuentran las de Sevilla, Manila, Cádiz y La Habana. A más distancia aparecen las de Santander y Gijón. El predominio de Barcelona se explica por la matriculación en ese puerto de la mayoría de los

47 Informe del armador Ricardo Sobrino a la Junta Pronincial de Agricultura, Industria y Comercio de Cádiz, Información (1879), t. I, p. 362. Ia Asociación de Navieros y Consignatarios de Barcelona indica algo similar, ibídem, p. 154.

48 La Habana $(90,3)$, Gijón (55,2), Barcelona (48,9), Santander (48,8) y Cádiz $(39,9)$ tenían porcentajes por encima de la media; los porcentajes de Manila $(9,9)$, Sevilla $(13,8)$ y Bilbao $(22,4)$ eran inferiores. 


\section{CUADRO 3}

Estructura por edad de la flota de vapor española en 1885

\begin{tabular}{lcccccc}
\hline & $0-5$ & $5-10$ & $10-15$ & $15-20$ & $20-25$ & $>$ de 25 \\
\hline TRB $\ldots \ldots \ldots \ldots \ldots \ldots \ldots$ & 119.131 & 64.003 & 67.406 & 20.888 & 17.567 & 11.373 \\
$\% \ldots \ldots \ldots \ldots \ldots \ldots \ldots$ & 39,7 & 21,3 & 22,4 & 6,9 & 5,8 & 3,8 \\
\hline
\end{tabular}

FUENTE: Elaboración propia de la L.O.B. de 1886. Buques mayores de 100 TRB.

buques de la Cía. Transatlántica, que monopolizaba la mayoría de los transportes subvencionados por el Estado: el 46 por 100 del tonelaje barcelonés pertenecía a esa compañía. Cádiz y Santander también deben su importancia a los buques de la Transatlántica y a los del Marqués de Campo matriculados en ellas. El tonelaje de los puertos de Bilbao, Sevilla y Gijón se dedica a satisfacer la demanda privada, bien en los tráficos de altura o bien los de cabotaje.

\section{CUADRO 4}

Estructura por matriculas del tonelaje de vapor español en 1885

\begin{tabular}{|c|c|c|c|}
\hline Matriculas & Número de buques & Tonelaje & $\%$ sobre el tonelaje total \\
\hline Barcelona & 66 & 97.022 & 29,6 \\
\hline Bilbao $\ldots$ & 83 & 78.942 & 24,1 \\
\hline Sevilla & 32 & 22.826 & 7,0 \\
\hline$\ldots \ldots \ldots \ldots \ldots \ldots \ldots$ & 40 & 21.678 & 6,6 \\
\hline Cádiz .......... & 11 & 20.651 & 6,3 \\
\hline La Habana ..... & 21 & 20.329 & 6,2 \\
\hline$\ldots \ldots \ldots \ldots \ldots \ldots \ldots$ & 12 & 13.736 & 4,2 \\
\hline 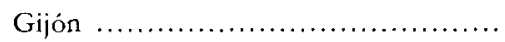 & 16 & 8.482 & 2,6 \\
\hline 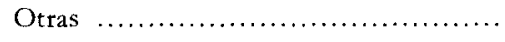 & 66 & 43.708 & 13,3 \\
\hline Total $\ldots$ & 347 & 327.374 & 100,0 \\
\hline
\end{tabular}

FuentE: Elaboración propia a partir de la L.O.B. de 1886. Buques $>$ de 100 TRB.

Las matrículas de Manila y La Habana se encuentran entre las seis primeras de España en 1885. No obstante, su protagonismo no se debe tanto a la presencia de una importante clase de armadores o compañias allí establecidas como a su localización estratégica en una navegación muy frecuentada por armadores españoles en estos años. Una gran parte de los 
armadores vascos, por ejemplo, habían adquirido sus buques en el Reino Unido con la ayuda financiera de capitalistas ingleses, buques empleados en la navegación entre Inglaterra y las colonias ${ }^{49}$. En lugar de hacer un viaje expreso a Bilbao para abanderar el buque, los navieros vascos optaron por abanderarlos en los puertos de Cuba y Filipinas. Posteriormente, todos esos buques acabaron siendo transferidos a la matrícula bilbaina. Desde finales de los años 70 sociedades como Olano, Larrínaga y Cía. y armadores como Eizaga, Yeves, Bergé, Arrótegui y Serra - todos, excepto este último, residentes en Liverpool y Londres - comienzan a matricular buques en Bilbao abanderados previamente en Cuba, Filipinas y Puerto Rico ${ }^{50}$ "

La tecnología del vapor permitía una mayor regularidad en los servicios de línea, y desplazó con gran rapidez a los buques de vela en los tráficos regulares oceánicos ${ }^{51}$. En España, como en Alemania, Gran Bretaña, Dinamarca o Japón ${ }^{52}$, la fase inicial de difusión del vapor fue protagonizada por grandes compañías que explotaban líneas regulares de navegación, algunas de las cuales estaban subvencionadas por el Estado a través de la concesión de servicios postales. El aumento en las necesidades de capital modificó los mecanismos tradicionales de financiación: el antiguo sistema de porciones fue sustituido por el surgimiento de compañías por acciones que podian reunir más fácilmente el capital necesario para comprar los nuevos buques ${ }^{53}$. A mediados de los años 80, las dos principales compañías navieras existentes en España estaban vinculadas a la explotación de servicios regulares subvencionados por el Estado, la Cía. Transatlántica, domiciliada en Barcelona, y la flota del Marqués de Campo, con residencia en Madrid. Tras ellas aparecían una serie de compañías bilbaínas y barcelonesas empleadas fundamentalmente en la navegación regular con las Antillas y con América del Sur y en los tráficos de gran cabotaje entre España e Inglaterra. En todas las bilbaínas hay una participación más o menos importante del capital inglés. En lo que respecta a las catalanas, la sociedad José Roca y Cía. era, en palabras de la Asociación de

49 Sobre esta cuestión, véase Valdaliso (1989).

50 Algunos traslados concretos se pueden ver en Registro de Buques de la Comandancia de Marina de Bilbao, lista 5.a, t. 1, fols. 145, 153, 154, 173, 191, 196 y 197. A este hecho se referirá Ramón de la Sota años más tarde cuando señale que "vizcainos establecidos en Liverpool, Manila, Habana, etc., sustituyeron los antiguos buques de vela por otros de vapor, creando en poco tiempo una flota de importancia», citado por Fernández de Pinedo (1988), pp. 278-79.

51 Davies (1978), p. 184, indica que en los años 70 el tráfico de línea internacional estaba completamente dominado por los buques de vapor.

52 Sobre Alemania, véase Scholl (1985), pp. 193-97. Sobre el Reino Unido, Davies (1978), pp. 184-88; Jackson (1988), pp. 267-70, y Broeze (1989), pp. 2 y ss. Sobre Japón, Nakagawa (1985), pp. 2-6, y Miwa (1985), pp. 124-34. Sobre Dinamarca, Hornby (1985), pp. 158-64.

53 Valdaliso (1991a). 
Navieros y Consignatarios de Barcelona, una «mera sucursal de Mac-Andrews y Compañía de Londres» ${ }^{54}$. Otra de las principales empresas catalanas, Tintoré y Cía., también estaba controlada por capital británico ${ }^{55}$. Durante los años ochenta se produjo una intensa reorganización de las compañías navieras existentes y el nacimiento de otras nuevas. Todas ellas adquirieron nuevas unidades, dedicadas generalmente al servicio de tráficos de línea ya existentes o a otros que se crean ahora en navegaciones protegidas como el cabotaje y la navegación con las colonias, mucho más intensa y activa que en épocas anteriores ${ }^{56}$. No obstante, entre las compañias de nueva creación surgieron algunas dedicadas a la navegación tramp, preludiando su apogeo posterior en los años noventa. Este incremento de la inversión en la marina mercante se produjo estimulado por la fuerte subida de los fletes de los primeros años ochenta ${ }^{57}$.

CUADRO 5

Estructura empresarial de la flota de vapor española en 1885

\begin{tabular}{|c|c|c|c|}
\hline Armador o Cia. & Domicilio & N.o buques & Tonelaje \\
\hline Cía. Transatlántica & Barcelona & 25 & 64.207 \\
\hline Marqués de Campo & Madrid & 19 & 32.505 \\
\hline José Roca y Cía. & Barcelona & 17 & 14.242 \\
\hline Cía. de Navegación La Flecha .............. & Bilbao & 10 & 11.716 \\
\hline Linea de Vapores Serra .................. & Bilbao & 9 & 11.305 \\
\hline Manuel M.a Arrótegui $\ldots \ldots \ldots \ldots \ldots \ldots \ldots$ & Bilbao-Liverpool & 7 & 9.866 \\
\hline Juan Bta. Morera y Cía. .................. & Barcelona & 3 & 9.086 \\
\hline Olano, Larrínaga y Cía. .................... & Bilbao-Liverpool & 9 & 7.232 \\
\hline Miguel Sáenz y Cía. ............. & Sevilla & 9 & 6.744 \\
\hline 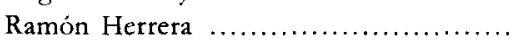 & La Habana & 6 & 5.948 \\
\hline
\end{tabular}

FUENTE: Elaboración propia a partir de la L.O.B. de 1886.

Los efectos hacia adelante de la modernización de la flota en lo que al transporte del comercio exterior español se refiere no fueron perceptibles

54 Información (1879), I, pp. 279 y 287.

55 Carrera Pujal (1961), p. 126.

56 Así lo indica el cónsul inglés en Barcelona en 1881 y 1882, véase PP, Commercial Reports, 1882, LXX, Barcelona, p. 238; 1882, LXXII, p. 422. En este puerto aparecen la Cia. Catalana de Vapores Trasatlánticos, la Cía. de Transportes Maritimos, la Cia. Barcelonesa de Vapores Trasatlánticos y Sala y Vidal, todas ellas dedicadas a la navegación regular transatlántica.

57 Véase el comercio de Angier en 1881, FF, 19-II-1920, p. 659. El alza de los fletes fue general en los tráficos internacionales y en aquellos donde operaban los buques españoles; sobre esta cuestión, véase Valdaliso (1991a). 
hasta principios del siglo Xx. En el conjunto del país, el tonelaje transportado por la bandera española se mantuvo en niveles muy bajos desde 1875 hasta finales del siglo XIX. Aunque a partir de 1870 se produjo un moderado descenso de la participación del pabellón nacional en el comercio exterior de España, ese descenso porcentual ocultaba un crecimiento importante de la carga transportada por la bandera española. Los navieros españoles controlaban una porción menor del comercio exterior de su país. Sin embargo, disponian ahora de un volumen superior de carga para transportar. La pérdida de cuota de mercado fue mayor en el puerto de Bilbao: el pabellón español pasó de transportar un 44 por 100 del volumen del comercio exterior en 1865-69 a un 20 por 100 en el quinquenio siguiente y a tan sólo un 9 por 100 en los primeros años ochenta. De ahí que tras la liberalización deĭ sector, la mayoría de los nuevos buques adquiridos se emplease en la navegación de cabotaje o en la de altura, concretamente en el tráfico colonial con las Antillas y Filipinas, única navegación protegida de la competencia extranjera.

\section{CUADRO 6}

Comercio exterior de España (Tm) transportado por el pabellón nacional, 1850-1899

\begin{tabular}{|c|c|c|c|c|}
\hline \multirow[b]{2}{*}{ Periodos } & \multicolumn{2}{|c|}{ España } & \multicolumn{2}{|c|}{ Bilbao } \\
\hline & $\% *$ & Tonelaje medio & $\% *$ & Tonelaje medio \\
\hline $1850-54$ & 47,4 & 590.106 & & \\
\hline $1855-59$. & 30,8 & 418.165 & 55,2 & 32.051 \\
\hline $1860-64 \ldots$. & 24,2 & 428.893 & 40,1 & 41.982 \\
\hline $1865-69 \ldots$. & 27,7 & 510.963 & 44,5 & 55.180 \\
\hline $1870-74 \ldots \ldots$. & 24,3 & 678.000 & 20,1 & 64.645 \\
\hline $1875-79 \ldots \ldots$ & 18,9 & 755.600 & 11,3 & 83.298 \\
\hline $1880-84 \ldots \ldots$. & 14,5 & 1.165 .985 & 8,8 & 278.200 \\
\hline $1885-89 \ldots \ldots \ldots$ & 17,8 & 1.714 .125 & 10,1 & 387.752 \\
\hline (n................. & 19,5 & 2.175 .331 & 15,0 & 706.214 \\
\hline 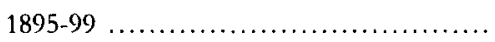 & 19,8 & 2.555 .048 & 14,3 & 762.667 \\
\hline
\end{tabular}

FuENTE: Elaboración a partir de las Estadísticas del Comercio Exterior de España, 1850-1899.

* Porcentaje respecto al comercio exterior total.

Tras la suspensión del derecho diferencial de bandera surgen en Barcelona algunas protestas, protagonizadas por el Fomento del Trabajo Nacional. Sin embargo, no parece que cuenten con un respaldo decidido de los navieros ${ }^{58}$.

58 Véase Izard (1979), pp. 142-43. 
A partir de 1872, tras la supresión definitiva de las tarifas protectoras, la marina de vela comienza a declinar rápidamente ante la competencia de los buques extranjeros. Este hecho, generalizado en todas las matrículas, repercutió especialmente en la de Barcelona. Los navieros de esta plaza comienzan a movilizarse a mediados de los 70. En 1876 envian una exposición al Ministerio de Hacienda «sobre la necesidad de favorecer las expediciones directas para fomentar la navegación de altura e impedir su decadencia» ${ }^{59}$. Ese mismo año, «a consecuencia de la triste situación de la marina mercante española» ${ }^{60}$, se constituye la Asociación de Navieros y Consignatarios de Barcelona. Finalmente, consiguen que el gobierno nombre una comisión encargada de analizar las consecuencias del derecho diferencial de bandera y de proponer las medidas necesarias para el desarrollo de la marina mercante nacional.

La comisión se forma por real decreto de 8 de septiembre de 1878, prolongando su actividad hasta 1883 , año en el que emite su dictamen definitivo. Durante este período el comportamiento de los navieros españoles deja de ser homogéneo. Por un lado, se encuentran los navieros catalanes, liderados por los de Barcelona, favorables al restablecimiento total o parcial del derecho diferencial. Para ellos, su supresión ha sido la causa directa de la crisis de la marina mercante. Por otro, están los armadores de Bilbao, Santander, Alicante y algunos de los de Cádiz, entre otros, contrarios al restablecimiento del derecho diferencial, para quienes el problema de la marina mercante española tiene que ver con el cambio técnico que se está produciendo en la navegación mundial que con la desaparición de aquel derecho. Finalmente, estos últimos logran imponer sus criterios en el dictamen final de la comisión.

Las protestas de los armadores catalanes perseguían un objetivo más concreto que el restablecimiento íntegro del derecho diferencial, aunque en sus exposiciones achacasen a éste la responsabilidad última en la crisis de la flota española ${ }^{61}$. No es casual que sus protestas se inicien a mediados de los años setenta, justo cuando comienza a ponerse en práctica por el gobierno el nuevo régimen de tratados comertciales con el objetivo de fomentar el

59 Izard (1979), pp. 144-45.

60 Información (1879), t. I, p. 144.

61 Responsabilidad que no estaba tan clara, por lo menos para algunos de ellos. En el apéndice número 12 del informe de la Junta de Agricultura, Industria y Comercio, Pablo María Tintoré reconocía que la causa fundamental de la crisis era «el cambio que ha experimentado de algunos años a esta parte a consecuencia de los progresos que se han hecho en la navegación, puesto que la navegación a vapor va sustituyendo a la de vela», véase Izard (1979), pp. 148-149, n. 7. Curiosamente, este apéndice no aparece en el informe que la Junta presenta a la comisión. 
comercio exterior. De hecho, las reivindicaciones de los navieros no son sino una más de las manifestaciones proteccionistas de los intereses económicos catalanes ante el nuevo régimen arancelario que culminará en la década siguiente. Para la Junta de Agricultura, Industria y Comercio la supresión del derecho diferencial de bandera había provocado la ruina de la marina mercante nacional: desde 1868 «los buques españoles han perdido por completo las mercancías de mucho peso y poco valor, que disputábamos a los ingleses y otros extranjeros, y van perdiendo por momentos las de mucho valor y poco peso de las que éramos únicos importadores». La estrategia de los navieros catalanes ante la pérdida de mercados es refugiarse en el único protegido, el tráfico con las Antillas: «Hoy ya no nos queda otro mercado para nuestros buques y aun para la mayor parte de los productos de nuestra nación», dirán, "que el mercado de la isla de Cuba». Su verdadero interés no radica en el restablecimiento completo del derecho diferencial de bandera, sino en su mantenimiento para la navegación con las colonias. $O$ más aún, en que la navegación con las Antillas y Filipinas sea declarada como si fuera de cabotaje, lo que suponía excluir completamente a los extranjeros de este tráfico. De ahí que no soliciten el restablecimiento completo del derecho diferencial de bandera, sino otra serie de medidas como primas a la navegación, recargo a terceros pabellones, la unificación de los impuestos, y, sobre todo,

El cabotaje con Cuba y demás Antillas y Filipinas, esto es, la navegación exclusivamente en bandera nacional para el tráfico de carga y pasajeros, entre nuestras provincias de ultramar y la peninsula y el planteamiento del verdadero cabotaje para las mercancias, he aquí el primer paso para solventar y resolver crisis $\tan$ tremendas 62 .

La Asociación de Navieros y Consignatarios de Barcelona, presidida por Federico Nicolau, uno de los navieros integrantes de la ponencia, se expresaba en términos más rotundos sobre la supresión del derecho diferencial de bandera. Además de proponer el establecimiento del cabotaje entre los puertos de la península y los de las Antillas y Filipinas ${ }^{63}$, la asociación defendia una amplia

62 Información (1879), t. I, p. 132. En parecidos términos se expresa Estasen (1880), pp. 69-70.

63 «Si acaso las consideraciones de no ser bastante suficiente el material de nuestras naves para el tráfico con nuestras provincias antillanas, aconsejaron ayer dar participación en él con ciertos recargos a la bandera extranjera, hoy no pueden aquéllas invocarse ... las desgracias mismas acumuladas por la legislación sobre nuestra marina han aumentado considerablemente el número y buenas condiciones de nuestro mejor material maritimo que ha convergido a este tráfico, único hospitalario para nuestra bandera ... La declaración del cabotaje completamente 
gama de medidas entre las que se encontraban la denuncia de los tratados de comercio y el restablecimiento completo del derecho diferencial de bandera ${ }^{64}$.

Las aspiraciones de los comerciantes y navieros catalanes respecto a la navegación y el comercio con las Antillas y Filipinas van a ser finalmente aprobadas por la Administración. Las leyes de 24 de junio y 26 de julio de 1882 asimilaban el tráfico entre aquellas islas y los puertos de la península al de cabotaje, estableciendo un periodo transitorio durante el cual se irian rebajando gradualmente los derechos de importación de productos de la metrópoli hasta llegar a eliminarlos en 1891. Durante ese mismo período se procedería gradualmente a la supresión del derecho diferencial de bandera en las colonias ${ }^{65}$. Serrano se ha referido a estas leyes como «compensaciones» otorgadas por el Gobierno a los sectores que podían haberse visto perjudicados por el nuevo régimen arancelario ${ }^{66}$. Ciertamente, así parece haber sido. Los representantes catalanes en la comisión, una vez conseguido su principal objetivo, acabaron firmando el dictamen final, aunque emitiendo un voto particular sobre la navegación con ultramar que intentaba asegurar, también durante el período transitorio, el monopolio de aquella navegación para los buques españoles ${ }^{67}$.

De entre todos los informes de los navieros contrarios al restablecimiento del derecho diferencial de bandera el emitido por la Junta de Agricultura, Industria y Comercio de Vizcaya es el más rotundo en sus aseveraciones. Empieza matizando que la supresión de aquel derecho se refería únicamente a

exclusivo para la bandera española sin concurrencias extranjeras produciria, al contrario, un aumento considerable en el tonelaje que se dedique a dicha navegación, y por este lado contribuirá a salvar nuestra marina mercante nacional», Información (1879), t. I, p. 203.

64 Información (1879), t. I, pp. 212-218.

65 La medida coincidia con una coyuntura difícil para la producción agraria española; véase Maluquer (1974), pp. 346-47, y Serrano (1987), pp. 66-67. En un principio la ley no establecía igual reciprocidad para los artículos de las colonias. Sin embargo, la situación crítica de Cuba empujó a la administración a liberalizar la entrada en España del azúcar antillano en 1884 y de otros productos coloniales en 1887. Sobre este problema, véase Serrano (1987), pp. 67-71.

66 Serrano (1987), p. 64.

${ }_{67}$ El voto fue presentado por Federico Nicolau y suscrito por Hilario Nava y Angel Cousillas. Según el mismo, las progresivas rebajas y franquicias que establecían las leyes de 24 de junio y 9 de julio de 1882 en las relaciones comerciales con las Antillas y Filipinas «sólo deben aplicarse a los productos nacionales conducidos en bandera española ... hasta tanto que el comercio y navegación desde los puertos de la península y los de la isla de Cuba, Puerto Rico y Filipinas y viceversa queden de cabotaje por la franquicia completa de derechos para la bandera española», Información (1883), pp. 320-1. Para Nicolau, «es tanto cl riesgo que ofrece la expresada abolición, que es muy posible se hagan sentir sus resultados desfavorables en la navegación a ultramar antes que pueda entrar nuestra Marina mercante de lleno en el cabotaje, y sería muy conveniente que se anticipara éste para los efectos de dichas navegaciones a los últimos plazos de las rebajas graduales", ibídem, p. 150. 
las importaciones de la península, y éstas habían crecido. Aunque el pabellón español ha perdido algunos tráficos como el de bacalao, «el tonelaje perdido por nuestra bandera, por este concepto, apenas daría empleo a cuatro vapores de 300 toneladas de registro durante el añom. Para la Junta, la crisis de la marina mercante española se inserta en una crisis mundial que afecta a todas las flotas mercantes provocada por la sustitución de la vela por el vapor en la mayor parte de las rutas comerciales ${ }^{68}$. No obstante, la Junta reconoce que la crisis ha sido más fuerte en la matrícula española por las propias caracteristicas del tonelaje de vela nacional:

Los buques de vela nacionales ... han sufrido aún con más rigor que los de otras naciones, la revolución del vapor, por las razones mencionadas, que les han reducido los mercados propios, y por no poder acudir a los extranjeros por las siguientes: porque son de poco tamaño para dedicarse a las navegaciones en que aun ha influido poco el vapor, como son las de la India, China, California, etc., ... porque no estamos hoy en situación de competir con el extranjero en el extranjero ...; porque no exigiendo nuestro comercio y compañias de seguros clasificación a los buques para darles y asegurarles carga, la inmensa mayoría no tienen clase en los registros acreditados en el extranjero y no encontrarian carga por la dificultad de asegurarla ... nuestros buques de vela están destinados a desaparecer, a lo menos, en sus dos terceras partes; esto sucederá muy rápidamente, pues la mayor parte son de madera y viejos, y como no hay aliciente para repararlos, tendrán que desguazarlos; unos cuantos vapores más serán suficientes para suplir la falta de los buques de vela en las navegaciones protegidas, y a esto quedará reducida nuestra marina ${ }^{69}$.

Los navieros bilbainos proponen una reforma radical del marco institucional en que se desenvuelve el sector que imite la legislación inglesa. La respuesta de la Junta va a diferir radicalmente de la ofrecida por un gran número de pueblos de la costa. Mientras que en la primera se encuentran los grandes comerciantes bilbaínos, algunos de ellos con intereses en la navegación a vapor como Raimundo Real de Asúa ${ }^{70}$, Ramón Bergé, Manuel de Zuricalday o Juan Bautista Astigarraga; los manifiestos de los pueblos van a ser firmados por capitanes y pequeños armadores que defienden el restablecimiento del derecho diferencial de bandera y la asimilación, como tráfico de cabotaje, del realizado con las Antillas y Filipinas ${ }^{71}$.

68 Información (1879), t. I, pp. 385-386.

69. Información (1879), t. I, p. 386.

70 En Información (1979), t. I, p. 394, aparece erróneamente "de Arceo».

71 Los pueblos que envían manifiestos son los de Mundaca, Portugalete, Gáuteguiz de Arteaga, Elanchove, Ibarranguelua, Zumaya, Barrica, Lequcitio y Plencia. Véase Información (1879), t. I, pp. 394-400. 
La postura de la Junta de Santander es similar a la de Bilbao, insistiendo en las consecuencias del cambio técnico sobre la matrícula española, especialmente en el declive de la flota de vela, en el que poco o nada tiene que ver el derecho diferencial ${ }^{72}$. La Junta de Huelva dirá que «la abolición no ha influido en nada en la disminución sufrida por la matrícula de ésta, sino que habiéndose transformado la de vela en vapor, vienen menos buques españoles, que todos son de cabotaje» ${ }^{73}$. El informe de la Junta de Cádiz muestras opiniones dispares. Mientras algunos achacan a la supresión del derecho diferencial la crisis de la flota y solicitan, en algunos casos, el restablecimiento de éste, otros sostienen la postura de los navieros de Bilbao y Santander ${ }^{74}$. Los navieros de Sevilla, finalmente, consideran que la supresión ha sido perjudicial, pero reconocen su necesidad para fomentar el comercio y no son partidarios de su restablecimiento ${ }^{75}$.

El dictamen final de la comisión rechaza las quejas de los navieros catalanes. El aumento del comercio exterior gracias a la reducción de los aranceles y la abolición del derecho diferencial de bandera ha provocado que «desde aquella reforma los buques españoles han transportado más carga en todas las navegaciones, así en las de Europa y Africa como en las de altura, que antes de la citada época) ${ }^{76}$. La comisión acepta el hecho de que algunos navieros - no todos- se hayan visto perjudicados, pero la causa no reside en la supresión del derecho diferencial, sino en el fenómeno del cambio técnico que se está produciendo en la navegación mundial:

Ha acontecido en la locomoción marítima lo que en la terrestre: un nuevo motor mucho más poderoso y mucho más perfecto que el antiguo ha venido a disputar a éste el servicio que presta a la industria de los transportes, siendo mayor cada día la parte que el nuevo invento toma en nuestra navegación ... Al propio tiempo, el tamaño de los buques ha ido creciendo sucesivamente, y esta circunstancia, unida a la mayor rapidez y regularidad que proporciona el nuevo motor sobre el antiguo, han hecho imposible la competencia que con él pudiera sostener la navegación de vela, y han reducido considerablemente así el número de buques como el personal necesario para realizar el movimiento que antes se verificaba ... este crecimiento no ha podido impedir que sean vencidos, no por

72 Información (1879), t. I, pp. 22-24.

73 Información (1879), t. I, p. 25.

74 Los informes de J. Morales Borrero y Compañia, Viuda de Andrés Isorna, Ricardo Sobrino, Horacio Alcón, Salvador Viniegra, José de la Viesca, Ramón Cordero y Antonio Millán son partidarios del restablecimiento. Los de José Luis Díez y Antonio Zulueta, los últimos emitidos y los más extensos, sobre todo el del último, presidente de la Junta, se oponen, scñalando otras causas de la crisis y otros remedios a la misma.

75 Información (1883), p. 304.

76 Informacion (1883), pp. 310-11. 
la competencia extranjera, sino por el moderno invento, los buques antiguos que con él no luchan ni en la celeridad, ni en el precio, ni en la regularidad del transporte. Han podido quedar por ello armadores sin fletes y capitanes y marineros sin colocación, y por su perjuicio personal ... quieren sostener que hay ruina y hay destrucción de la Marina mercante, y la necesidad de restablecer el derecho de pabellón, como si de este modo pudiera luchar la nave pequeña de vela, que se mueve a merced del viento, con el buque de vapor de gran tamaño, rápido en su marcha y que navegará a voluntad del capitán ${ }^{77}$.

Para la comisión, «lo que necesita la Marina mercante para prosperar es tener mucha carga que conducir, y esto no se consigue con las primas y los privilegios, sino con la libertad del comercio, de la industria y de la navegación; con derechos arancelarios muy bajos, materias primäs muy baratas y armadores activos e inteligentes» ${ }^{78}$. Precisamente a la altura de 1880 la gran mayoría de los navieros era consciente de la imposibilidad de restablecer el derecho diferencial de bandera sin que al mismo tiempo se produjeran consecuencias nefasta para el comercio y el tráfico marítimo. Todos los círculos navieros conocían el fracasado intento de Francia de restablecer ese derecho en 1872 y su supresión, un año después, porque sus puertos abandonados en beneficio de otros extranjeros cercanos 79 . Los navieros españoles y los del Cantábrico en particular ya habían experimentado este problema unos años antes. La abolición del derecho diferencial había incrementado la competencia de los pabellones extranjeros, pero también estaba suponiendo un crecimiento importante del comercio exterior español. Pero, además, el nuevo régimen de tratados comerciales puesto en práctica desde mediados de los años setenta y generalizado en los ochenta excluía totalmente cualquier medida restrictiva del comercio, en cuanto que la mayoría de los tratados firmados se realizaron sobre la base de acuerdos preferenciales a través de la cláusula de nación más favorecida ${ }^{80}$. Incluso la propia actuación de los armadores catalanes que encabezaron los movimientos de protesta a partir de 1876 fue encaminada no al restablecimiento del derecho diferencial de bandera, sino a conseguir otro tipo de ventajas frente a los buques extranjeros que no repercutiesen en el comercio y, sobre todo, a obtener ventajas preferenciales en el tráfico y en el comercio con las Antillas y Filipinas mediante su asimilación al de cabotaje. Unicamente las «clases náuticas», marineros y oficiales, fueron firmes partidarias de su restableci-

\footnotetext{
77 Información (1883), p. 311.

78 Información (1883), pp. 319-20.

79 Información (1883), p. 300.

80 Serrano (1987), pp. 46-49.
} 
miento en cuanto que aseguraba - a corto plazo - el empleo de los buques de vela y, por tanto, el mantenimiento de sus puestos de trabajo. Ciertamente, a largo plazo era inevitable que la nueva tecnología, menos intensiva en trabajo, desplazase al velero, pero las causas de las movilizaciones suelen estar más ligadas a las acuciantes necesidades del presente que a las prometedoras perspectivas de un futuro más o menos lejano.

Las páginas anteriores han dado una explicación ex post de la transición de la vela al vapor en la flota mercante española que, implícitamente, parte a priori de que ese proceso se ha verificado históricamente con un relativo éxito desde una perspectiva internacional. Sin embargo, este planteamiento descuida el análisis de otro tipo de alternativas existentes para los navieros españoles, puesto que no responde adecuadamente a la pregunta de por qué éstos invirtieron en la compra de modernos buques de vapor adquiridos en el extranjero y no optaron por seguir invirtiendo en buques de vela o abandonar el negocio y dirigir sus inversiones hacia otros sectores económicos.

La pregunta no es ociosa. A la altura de 1860 la flota española - compuesta mayoritariamente por veleros de madera - se encontraba entre las diez más importantes del mundo y, además, estaba protegida de la competencia extranjera mediante un derecho diferencial; España, además, poseía una industria naval - dedicada a la construcción de buques de madera- de una cierta importancia. $\mathrm{Y}$, sin embargo, en el curso de dos décadas los veleros se vieron desplazados de las rutas en las que estaban empleados los buques españoles (Europa y América); la propia flota española tuvo que enfrentarse a la competencia de pabellones más modernos, puesto que el derecho diferencial fue suprimido en 1868 , y la industria naval desapareció casi por completo. La abolición del derecho diferencial de bandera puso de manifiesto la incapacidad de la flota de vela hispana para competir en precios con otras ! banderas; la decadencia de la vela se aceleró considerablemente a partir de 1872, cuando la protección quedó definitivamente suprimida, y de 1876, cuando sobrevino una depresión en el mercado internacional de transporte que afectó especialmente a los buques de madera propulsados a vela. En estas circunstancias los armadores españoles podían haberse dirigido hacia otras alternativas más rentables en el interior, al igual que hicieron los navieros canadienses en los años ochenta ${ }^{81}$. Sin embargo, aunque algunos lo hicieron,

\footnotetext{
81 Sager y Panting (1985), pp. 32-37.
} 
la mayoría continuó en el negocio vendiendo sus veleros en el extranjero y adquiriendo en su lugar buques de vapor. La elección pudo deberse a razones endógenas al propio sector - - en el lado de la oferta o en el de la demanda-o exógenas - ausencia de alternativas rentables de inversión en tierra firme.

Desde el lado de la demanda el proceso de difusión tecnológica coincidió con un incremento fuerte de la demanda derivada de transporte, sólo interrumpida por la crisis de la segunda mitad de los años setenta. Los barcos españoles transportaron un porcentaje menor del comercio exterior nacional, pero ese menor porcentaje significaba una demanda mayor para su flota. Sin embargo, la preocupación por proteger el tráfico colonial parece desmedida si tenemos en cuenta que el comercio con las Antillas no proporcionaba empleo a mucho tonelaje ${ }^{82}$. El principal producto de importación, el azúcar, ténía un mercado muy limitado en España, que apenas absorbia el 10 por 100 de las exportaciones cubanas ${ }^{83}$. Las principales exportaciones, harinas y vino, comenzaron a descender desde 1881 en el primer caso y desde 1886 en el segundo ${ }^{84}$. A partir de 1884 , además, el derecho diferencial que pesaba sobre la bandera extranjera que transportase productos del extranjero a las Antillas fue suprimido, equiparándose al pabellón nacional. El embajador de España en Washington señalaba que «la asimilación de banderas, punto capital de dicho modus viviendi y el único a que aspiraban los Estados Unidos, ha dado mayor incremento a su comercio de fletes, con detrimento de nuestra marina mercante» ${ }^{85}$. Pero el verdadero negocio de los navieros españoles en la navegación con las Antillas no residía en el tráfico de ida, sino en el de vuelta, transportando azúcar desde Cuba a Estados Unidos y retornando desde allí a Europa con cereales o algodón. A finales de los años 80, el cónsul español en Liverpool indicaba que

... Los buques que hacen viajes periódicos a y de Cuba y Puerto Rico, ya toquen o no la Península, ordinariamente llevan cuando van tan poca carga, que muy bien podria transportar la de cinco o seis uno sólo. Lo que les sostiene es que de retorno comienzan su viaje desde los puertos de Cuba al de Nueva

82 A la altura de 1880 más del 60 por 100 de las importaciones y cxportaciones del comercio exterior español en bandera nacional se efectuaban con Europa. Il comercio con Cuba y Puerto Rico, que en 1860 había concentrado el 22 por 100 de las importaciones y el 54 por 100 de las exportaciones, representaba ahora el 6 y el 23 por 100, respectivamente. Véase Valdaliso (1991a).

83 Serrano (1987), p. 70.

84 Maluquer (1974), pp. 340-43.

85 Reforma Arancelaria (1890), t. V; memoria del enviado extraordinario y ministro plenipotenciario de España en Washington, p. 73. La medida fue tomada en el modus wivendi firmado con Estados Unidos e inmediatamente se aplicó a las importaciones antillanas procedentes de Francia, Alemania y Gran Bretaña. Véase Maluquer (1974), p. 347. 
York, generalmente cargados de azúcares y recorren otros puertos de los Estados Unidos, donde toman, casi siempre para Liverpool, algodón, granos y ganado. Sin este auxilio les sería muy difícil continuar... ${ }^{86}$.

Por esta razón, las principales compañias españolas que realizaban este tráfico, la Cia. Transatlántica y Larrinaga y Cia., salian siempre de Liverpool sin tocar generalmente los puertos de la península 87.

Además, el tráfico americano compensaba su menor volumen de carga con la mayor distancia que tenían que recorrer los buques. Estimando la demanda en función de las toneladas-millas recorridas y no únicamente en función del tonelaje transportado --véase cuadro 7--, observamos cómo el tráfico con América en bandera nacional fue muy superior al europeo desde 1860 a 1880 y similar en 1890. Dentro de América, el comercio con Cuba y Puerto Rico mantuvo un lugar preferente en los viajes de los vapores españoles durante la segunda mitad del siglo XIX. Las toneladas-millas de este tráfico supusieron, respecto a las transportadas por la bandera nacional en Europa, un 361 por 100 en 1860 , un 192 por 100 en 1870 y un 86 por 100 en 1880. La existencia de este mercado cautivo durante la transición de la vela al vapor significó una fuente de empleo fundamental para los nuevos vapores españoles. Por eso la mayor parte de las compañias vascas y catalanas creadas en los años setenta y ochenta organizaron servicios de línea y no se dedicaron a la navegación tramp, en la que, además, el buque de vela seguía ofreciendo una cierta competencia.

Con una demanda creciente y, lo que es más importante, parcialmente cautiva, los navieros españoles optaron por optimizar su experiencia empresarial y su conocimiento de los mercados aplicándolos a la nueva tecnología, especialmente adecuada a los tráficos donde éstos operaban. Pero, además, la tecnología del vapor y el aumento en el tamaño de los buques hizo descender la participación de los costes salariales en el conjunto global de los costes de explotación del buque gracias a la reducción del número de tripulantes por

86 Reforma Arancelaria (1890), t. V; memoria del cónsul de España en Liverpool, pp. 195-96. Por este motivo el mantenimiento de unas buenas relaciones comerciales con los Estados Unidos era indispensable, no sólo para asegurar la exportación de azúcar cubano, sino también para mantener la navegación de los buques españoles. Cuando en 1890 Estados Unidos restringe radicalmente sus importaciones de azúcar la diplomacia española se precipita rápidamente a firmar un nuevo tratado con aquel país (1891) con el objetivo de mantener ese mercado para los productos antillanos. Sobre esta cuestión, véase Maluquer (1974), pp. 347-48, y Serrano (1987), p. 71 .

87 Ibídem. La primera tenía empleados diez vapores en viajes periódicos desde Liverpool a Cuba y Puerto Rico; la scgunda sicte. 


\section{CUADRO 7}

Estimación de las toneladas-millas demandadas por el comercio exterior en bandera nacional con Europa y América, 1860-1900 (años seleccionados)

\begin{tabular}{|c|c|c|c|c|c|c|c|}
\hline & \multirow[b]{2}{*}{ Años } & \multicolumn{2}{|c|}{ Comercio con Europa } & \multicolumn{2}{|c|}{ Comercio con América } & \multicolumn{2}{|c|}{$[(3) /(1)][(4) /(2)]$} \\
\hline & & $\begin{array}{c}T m \# \\
\text { (1) }\end{array}$ & $\begin{array}{c}\text { Tons-millas \# } \\
(2)\end{array}$ & $\begin{array}{c}T m \# \\
(3)\end{array}$ & $\begin{array}{c}\text { Tons-millas\# } \\
\text { (4) }\end{array}$ & $\begin{array}{c}* 100 \\
(5)\end{array}$ & $\begin{array}{c}* 100 \\
(6)\end{array}$ \\
\hline 1860 & & 136 & 185.775 & 233 & 1.023 .720 & 171,3 & 551,0 \\
\hline 1870 & & 286 & 391.509 & 237 & 1.040 .834 & 82,8 & 265,8 \\
\hline 1880 & & 581 & 794.637 & 262 & 1.147 .901 & 45,1 & 144,4 \\
\hline 1890 & & 1.522 & 2.081 .257 & 474 & 2.080 .351 & 31,1 & 100,0 \\
\hline 1900 & & 4.169 & 5.698 .476 & 376 & 1.649 .449 & 9,0 & 28,9 \\
\hline
\end{tabular}

Fuente: Elaboración a partir de las ECEE para el volumen de comercio y de Bilbao, XVII, 826 (1911), p. 102; y 833 (1911), p. 204, para la distancia.

La distancia media a Europa - -1.367 millas - se basa en la media aritmética de las distancias desde Bilbao y Barcelona a los puertos de Londres, Liverpool, Middlesbrough y Newcastle en Gran Bretaña; y de Rotterdam en Holanda. La distancia media a América - 4.388 millas - se basa en la media aritmética de las distancias desde Bilbao y Barcelona a La Habana, punto medio en el tráfico con América.

\# Miles de toneladas.

tonelada de arqueo y a la estabilidad de los salarios ${ }^{88}$. La combinación de todos estos factores elevó considerablemente el coste de oportunidad de abandonar el negocio e invertir en otros sectores productivos.

Queda por examinar si en los años setenta existieron alternativas rentables de inversión en tierra firme. En Cataluña todo parece indicar que una parte de los capitales invertidos en la flota mercante se desviaron en este década hacia negocios de rentabilidad asegurada, como las acciones ferroviarias, o hacia sectores en expansión como el textil ${ }^{89}$. En Vizcaya, por el contrario, no parece que se diera un proceso similar. El crecimiento del sector siderúrgico se produjo más tarde, entre 1879 y 1882 , cuando se registra el grueso de la inversión en el sector ${ }^{90}$. La existencia de diferentes oportunidades para la

88 Sobre esta cuestión, véase Valdaliso (1991a).

89 La Junta Provincial de Agricultura, Industria y Comercio de Barcelona señalaba en su informe de 1879: "¿Qué sucederá si estudiamos el cúmulo de capitales que ha creado la marina mercante en nuestra provincia y que se han invertido en acciones de ferrocarriles, en participación en fábricas de hilados y tejidos, y hasta en mejoras agrícolas de la mayor importancia?", Información $(1879)$, t. I, p. 125. El crecimiento del sector textil catalán continuó hasta 1880 según Nadal (1975), p. 209, ligado al progreso agrícola.

90 Fernández de Pinedo (1988). Los índices de producción industrial de Carreras para el Pais Vasco (1985b) también documentan esta afirmación. La única excepción parece ser la de Olano, que dejó sus negocios maritimos por los siderúrgicos de la Vizcaya, véase Valdaliso (1991a). 
inversión de catalanes y vascos probablemente influyó en el futuro de sus respectivas flotas. En todo caso, es una hipótesis a corroborar con investigaciones más detalladas que cuantifiquen, especialmente en el caso catalán, el posible volumen del capital naviero invertido en otros sectores.

Aunque divergentes en cuanto a las causas, la mayor parte de los autores han atrasado los orígenes de la flota de vapor española a los últimos años del ochocientos, flota que estaría registrada mayoritariamente en Bilbao y vinculada a los tráficos libres europeos. Esta descripción coincide con una etapa de expansión del sector, pero no con su surgimiento. Como he señalado a lo largo de estas páginas, el nacimiento de la flota mercante de vapor en España se produjo en la década de los setenta del siglo XIX y estuvo vinculado a una serie de cambios, decisivos, producidos en la tecnologia, el marco institucional y los mercados donde los navieros operaban. En esta coyuntura vascos y catalanes, pero también montañeses o gaditanos, optaron decididamente por el buque de vapor. La evolución posterior a partir de los años finiseculares consolidó la posición de los vizcaínos y debilitó la del resto, pero esa crisis no debe oscurecer su pasado anterior ${ }^{91}$.

91 Sobre la distribución por matrículas de la flota hispana, véase Valdaliso (1991b). 


\section{BIBLIOGRAFIA}

AlzolA, Benito (1886): Estudio relativo a los recursos de que la industria naval dispone para las construcciones y armamentos navales, Madrid, Imprenta de la Infantería de Marina.

-- (1984): Las primas a la construcción naval y a la navegación. Datos y noticias que conviene tener presentes para hacer una ley sobre la materia, Bilbao, Imprenta de la Casa de Misericordia.

Angier, E. A. V. (1920): Fifty Years' Freights, 1869-1919, Londres, Fair Play.

BROEZE, Frank (1989): «Distance tamed: steam navigation to Australia and New Zealand from its beginnings to the outbreak of the Great War», en Journal of Transport History, 10, 1, 1-21.

Carrea Pujal, Jaime (1961): La economía de Cataluña en el siglo XIX, tomo IV: marina mercante, puertos, carreteras y ferrocarriles, Barcelona, Bosch.

Carreras, Albert (1985): «La producción industrial catalana y vasca, 1844-1935. Elementos para una comparación», en GonzÁlez PorTilla, M.; MALuquer DE Motes, J.; Riquer Permanyer, B. (eds.): Industrialización y nacionalismo. Análisis comparativos. Actas del I Coloquio Vasco-Catalán de Historia, Barcelona, Universitat Autonoma, pp. 197-209.

COstas Comesaña, Antón (1988): Apogeo del liberalismo en "La Gloriosa». La reforma económica en el sexenio liberal (1868-1874), Madrid, Siglo XXI.

Craig, Robin (1980): The Ship. Steam tramps and Cargo liners 1850-1950, Londres, National Maritime Museum.

Davies, Peter N. (1978): «The Development of the Liner Trades», en MatThews, K., y Panting, G. (eds.): Ships and Shipbuilding in the North Atlantic Region, Newfoundland, Memorial University, pp. 173-206.

ESTASEN Y CORTADA, Pedro (1880): El comercio y la marina mercante española. Informe sobre las consecuencias que ba producido la reforma arancelaria del señor Figuerola, Barcelona, Imprenta de los Sucesores de N. Ramírez y C.a

FERNÁNDEZ DE PINEDO, Emiliano (1986): «El desarrollo de Bilbao y de sus actividades (1300-1936)", en Catálogo de la Exposición Centenario (1886-1986) de la Cámara de Comercio, Industria y Navegación de Bilbao, Bilbao.

- (1988): «Factores técnicos y económicos en el origen de la moderna siderurgia y la flota vizcaína, 1880-1899", en FERnÁndeZ de PINEdo, E., y HernándeZ MARCO, J. L., eds., La industrialización del norte de España, Barcelona, Critica, pp. 252-279.

FISHER, Lewis, R., y SAGER, Eric WW. (1986): Shipping and Shipbuilding in Atlantic Canada 1820-1914, Otawa, Canadian Historical Association.

-..-, y NORDVIK, Helge W. (1986): «Maritime Transport and the Integration of the North Atlantic Economy, 1850-1914», en Fischer, W.; MCINnIS, R. M., y SChNeider, J. (eds.): The Emergence of a World Economy, 1500-1914, Part II: 18501914, Wiesbaden, Franz Steiner Verlag Wiesbaden GmbH, pp. 519-544.

Fletcher, M. E. (1958): "The Suez Canal and World Shipping, 1869-1914», en Journal of Economic History, XVIII, 556-573.

GJOLBERG, Ole (1980): «The substitution of steam for sail in Norwegian Ocan Shipping, 1866-1914. A study in the Economics of diffusion», en Scandinavian Economic History Review, XXVIII, 2, 135-146. 
GÓmEz MENDOZA, A. (1988): «Government and the development of modern shipbuilding in Spain, 1850-1935», en Journal of Transport History, 9, 1, 19-36.

(1989): "Transportes y comunicaciones", en CARRERAS (coord.): Estadisticas bistóricas de España de España. Siglos XIX-XX, Madrid, Fundación Banco Exterior, pp. 269-325.

GONZÁlez PORTILla, J. M. 81981): La formación de la sociedad capitalista en el Pais Vasco, 1876-1913, San Sebastián, Haranburu.

GRAHAM, Gerald S. (1956): "The ascendancy of the sailing ship, 1850-85», en Economic History Review, IX, pp. 74-88.

HARLf., Charles K. (1971): "The shift from sailing ships to steamships, 1850-1890: a study in technological change and its diffusion», en MCCLOSKEY, D. N. (ed.): Essays on a mature economy: Britain after, 1840, Londres, Methuen Co. Ltd., pp. 215-237.

HeADrick, Daniel R. (1988): The Tentacles of Progress. Tecbnology Transfer in the Age of Imperialism, 1850-1914, Oxford, Oxford University Press.

Hornby, O.; Nilsson, C. A. (1980): "The transition from sail to steam in the Danish Merchant Flett, 1865-1910", en Scandinavian Economic History Review, XXVIII, 2, 109-134.

(1985): «The Danish Shipping Industry, 1866-1939: Structure and Strategy», en YUI, T., y NAKAGAWA, K. (eds.): Business History of Shipping. Strategy and Structure, Tokyo, University of Tokyo Press, pp. 157-181.

_- Información sobre el Derecho Diferencial de Bandera y sobre los de aduanas exigibles a los bierros, el carbón de piedra y los algodones, presentada al Gobierno de Su Majestad por la Comisión nombrada al efecto en Real Decreto de 10 de noviembre de 1865, $t$. I: Derecho Diferencial de Bandera; t. II: Hierros; t. III: Carbones; t. IV: Algodones (1867), Madrid, Imprenta Nacional.

- Información sobre las consecuencias que ba producido la supresión del Derecho Diferencial de Bandera y sobre las valoraciones y clasificaciones de los tejidos de lana, formada con arreglo a los articulos 20 y 29 de la Ley de Presupuestos del año 1878-1879, por la Comisión Especial arancelaria creada por Real Decreto de 8 de septiembre de 1878 , t. I: Derecho Diferencial de Bandera; t. II: Industrial lanera (1879); t. II: Industrias lanera y naviera. Discusión y aprobación de los dictámenes (1883), Madrid, Imprenta de Manuel Minuesa de los Ríos.

IZARD, Miquel (1979): Manufactureros, industriales y revolucionarios, Barcelona, Crítica. JACKSON, G. (1988): "The shipping industry», en ALDCROFT, DEREK H.; FFrEEMAN, MICHAEL, J.: Transport in the Industrial Revolution, Manchester, Manchester University Press, pp. 253-283.

JiMENo Agius, J. (1889): La marina mercante en España y en el extranjero, Madrid, Imprenta de Enrique Maroto y Hermano.

KaUkIAINEN, Yrjo (1980): «The transition from sail to steam in Finish Shipping, 1850-1914», en Scandinavian Economic History Review, XXVIII, 2, 161-184.

KRESSE, W. (1985): «The Shipping industry in Germany, 1850-1914», en FisCHER, L. R., y PANTing, G. E. (eds.): Change and adaptation in maritime history. The Nortb Atlantic fleets in the Nineteenth century, Newfoundland, Memorial University, pp. 149-167.

MALUQUER DE MOTES, J. (1974): «El mercado colonial antillano en el siglo XIX», en 
Nadal, J. y TORTella, G. (eds.): Agricultura, comercio colonial y crecimiento económico en la España contemporánea, Actas del I Coloquio de Historia Económica de España, Barcelona, Ariel, pp. 322-357.

Martínez Alcubilla, M. (1923): Diccionario de la Administración Española, Madrid. MATTHEWS, Keith (1979): "The Canadian deep sea merchant marine and the American export trade, 1850-1890\%, en AleXANDER, David; OMmer, Rosemary (eds.): Volumes not values: Canadian sailing ships and World Trades, Newfoundland, Memorial University, pp. 197-243.

MrWA, R. (1985): «Maritime Policy in Japan: 1868-1937», en YUI, T., y NAKAGAWA, K. (eds.): Business History of Shipping. Strategy and Structure, Tokyo, University of Tokyo Press, pp. 123-152.

NADAL OlLER, Jordi (1975): El fracaso de la revolución industrial en España, 1814-1913, Barcelona, Ariel.

(1988): «España durante la primera revolución tecnológica», en NAỈAL, Jordi; Carreras, Albert; MArtín ACEÑA, Pablo: España, 200 años de tecnologia, Madrid, Ministerio de Industria y Energía, pp. 29-100.

NAKAGAWA, K. (1985): "Japanese Shipping in the Nineteenth and Twentieth Centuries: Strategy and Organization», en YuI, T., y NAKAGAWA, K. (eds.): Business History of Shipping. Strategy and Structure, Tokyo, University of Tokyo Press, pp. 1-33.

NoRDVIK, H. W. (1985): "The Shipping industries of the Scandinavian countries, 1850-1914», en Fischer, L. R., y PANTING, G. E. (eds.): Change and adaptation in maritime bistory. The North Atlantic fleets in the Nineteenth century, Newfoundland, Memorial University, pp. 117-148.

PAlmer, S. (1978): «Experience, Experiment and Economics: Factor in the Construction of Early Merchant Steamships», en MATTHEws, K., y PANTING, G. (eds.): Ships and Sbipbuilding in the Nortb Atlantic Region, Newfoundland, Memorial University, pp. 231-247.

(1985): "The British Shipping industry, 1850-1914», en FISCHER, L. R., y Panting, G. E. (eds.): Change and adaptation in maritime bistory. The North Atlantic fleets in the Nineteentb century, Newfoundland, Memorial University, pp. 87-114.

- Reforma Arancelaria y los Tratados de Comercio (La). Información escrita de la Comisión creada por Real Decreto de 10 de octubre de 1889 (1890), Madrid, IV tomos.

ROLDÁN, S., y GARCíA DELGADO, J. L. (1973): La formación de la sociedad capitalista en España, Madrid, CECA.

Rosenberg, Nathan (1979): Tecnologia y Economia, Barcelona, Gustavo Gili.

SAGER, E. W.; FISCHER, L. R.; OMMER, R. E. (1982): «Landward and Seaward Opportunities in Canada's Age of Sail», en FISCHER, Lewis R.; SAGER, Eric W. (eds.): Merchant Shipping and Economic Development in Atlantic Canada, Newfoundland, Memorial University, pp. 7-31.

, y PANTING, G. E. (1985): "Staple economies and the rise and decline of the Shipping industry in Atlantic Canada, 1820-1914), en FISCHER, L. R., y PANTING, G. E. (eds.): Change and adaptation in maritime bistory. The North Atlantic fleets in the Nineteenth century, Newfoundland, Memorial University, pp. 1-46.

SÁNCHEZ DE TOCA, Joaquín (1986): Del poder naval en. España y su politica económira para la nacionalidad iberoamericana, Madrid, Museo Naval. 
SCHOLL. L. U. (1985): «Shipping Business in Germany in the Nineteenth and Twentieth Centuries», en YUI, T., y Nakagawa, K. (eds.): Business History of Shipping. Strategy and Structure, Tokyo, University of Tokyo Press, pp. 185-213.

Serrano Sanz, José Maria (1987): El viraje proteccionista en la Restauración. La política comercial española, 1875-1895, Madrid, Siglo XXI.

TORRes Villanueva, Eugenio (1991): «Barcos, carbón y mineral de hierro. Los vapores de Sota y Aznar y los origenes de la moderna flota mercante de Bilbao, 1889-1900», en Revista de Historia Económica, IX, 1, 11-32.

VALDALiso GAGO, José María (1989): "Capital inglés y buques vascos en el tráfico colonial durante la segunda mitad del siglo XIX», comunicación presentada al IV Congreso de la Asociación de Historia Económica de España, Alicante.

-_. (1991a): Los navieros vascos y la marina mercante en España, 1860-1935. Una historia económica, Bilbao, Instituto Vasco de Administración Pública.

- (1991b): "Growth and Modernization of the Spanish Merchant Marine, 18601935», en International Journal of Maritime History, III, 1.

VICENS VIVES, J., y LLORÉns, M. (1958): Industrials i politics de segle XIX, Barcelona, Teide. 